\title{
A new terrestrial trace fossil Feoichnus martini n. isp. from the Upper Cretaceous Two Medicine Formation (USA)
}

\author{
Giulio Panascí @ and David J. Varricchio @
}

Department of Earth Sciences, Montana State University, Bozeman, Montana 59717-2760, USA <giulio.panasci87@ gmail.com>

<djv@montana.edu>

\begin{abstract}
A new trace fossil, Feoichnus martini new ichnospecies, from the Two Medicine Formation is here described. This ichnotaxon is reported from the upper Campanian deposits of the Egg Mountain locality (Montana) and consists of a hemispherical to hemiellipsoidal structure with a truncated upper edge, and a regular, rounded lower edge marked by a lined border composed of stained layers. The trace maker likely impregnated the border using organic fluids. The simple lined wall observed in F. martini $\mathrm{n}$. isp. suggests that the structure was produced by an invertebrate soildwelling organism, likely an insect. Specimens are preserved as casts in calcitic Inseptisols alongside an abundant vertebrate fossil record composed by dinosaurian and nondinosaurian fossil remains, dinosaur eggs and nest structures, and pervasive insect bioturbation. Feoichnus martini n. isp. represents an additional, minor component of the impoverished Celliforma ichnofacies reported at Egg Mountain and expands the paleogeographical distribution of the ichnogenus Feoichnus Krause et al., 2008 to the Upper Cretaceous deposits of Montana, USA.
\end{abstract}

UUID: http://zoobank.org/7c1a5026-7f27-4f12-a9fb-1eb8daa93baf

\section{Introduction}

Evaluating the mode of construction and preservation of a trace fossil is an important step toward the determination of the possible producer and provides the opportunity to investigate behavioral evolution of organisms in the past. Proper functional and taxonomic interpretation of a trace and its maker first depends upon understanding the preservation process, which could impact ichnologic fidelity, trace visibility, and ultimately ichnotaxonomy (Savrda, 2007; Buatois and Mángano, 2011, p. 12; Bromley, 1996, p. 155-158).

Paleosol ichnology has provided important insights on the evolution of dwelling strategies in terrestrial invertebrates. Trace fossils show that beginning in the Late Cretaceous, soil insects displayed a marked rise in both behavioral and taxonomic diversity with the use of constructed pelletal and fluidized linings to inscribe and stabilize the boundary walls of pupation chambers and cocoons (Genise, 2016, p. 565). Similar adaptations have been also reported in trace fossils ascribed to crustaceans, which perfuse with thick linings the walls of burrows and breeding chambers constructed in soils (Genise et al., 2008; Bedatou et al., 2008). This Late Cretaceous revolution is testified by a richer record of trace fossils within paleosols worldwide and exemplified by the occurrence of the Celliforma ichnofacies, the first insect-dominated ichnofacies (Genise et al., 2016).

Over the last 10 years, several studies have reported an abundant collection of trace fossils preserved in paleosols from the Upper Cretaceous Two Medicine Formation. These trace fossils have increased importance given their occurrence in dinosaur nesting grounds where they could provide environmental constraints on dinosaur reproductive strategies (Martin and Varricchio, 2011). So far, these studies have recognized an abundant insect trace-fossil assemblage ascribed to Fictovichnus sciuttoi Genise et al., 2007, Rebuffoichnus isp., Teisseirei isp., and Tombownichnus isp., interpreted, respectively, as hymenopterans pupation chambers, coleopterans brooding chambers, and perforation traces produced by parasitoid insects (Martin and Varricchio, 2011; Freimuth and Varricchio, 2019). Here we describe a novel enigmatic trace fossil from Two Medicine Formation deposits of the Egg Mountain locality-Feoichnus martini new ichnospecies-attributable to a possible insect trace maker. Even though the structure is very simple, we recognize several features, e.g., preferential orientation and presence of a thin discrete wall, which could suggest a mechanism of formation similar to that observed in other soil-preserved traces. This study: (1) provides a description of this new trace fossil, (2) discusses a possible mechanism of its formation and preservation, (3) analyzes it relative abundance with respect to other trace fossils from the same site, and (4) reviews its paleoenvironmental and paleoecological significance.

\section{Geological setting}

The Upper Cretaceous Two Medicine Formation crops out in northwestern Montana within the Rocky Mountain Disturbed Belt and is composed of siliciclastic sediments derived from the erosion of the uplifting Sevier Thrust Belt and igneous effusive rocks of the Elkhorn volcano (Lorenz and Gavin, 1984). Two Medicine Formation sediments were deposited in fluviolacustrine settings extending between the thrust belt to the west and the Western Interior Seaway to the east (Rogers, 1990). Semiarid climate conditions influenced by monsoonal 
regimes are suggested for the Two Medicine Formation by evidence from the lines of arrested growth in conifer log fossils, the common occurrence of caliche nodules, and the scarcity of root traces in the succession (Lorenz and Gavin, 1984; Retallack, 1997; Falcon-Lang, 2003). The abundance of insect trace fossils ascribed to fossorial hymenopterans in paleosols corroborates this interpretation (Martin and Varricchio, 2011; Freimuth and Varricchio, 2019).

Egg Mountain is located $19 \mathrm{~km}$ west of Choteau, Montana and is part of the Willow Creek anticline (Fig. 1). The site is located $\sim 1.5 \mathrm{~km}$ south of the Pupa Peninsula (PPP), where paleosols stratigraphically equivalent to Egg Mountain have revealed a notable invertebrate ichnoassemblage mainly composed of insect pupation chambers and cocoons (Martin and Varricchio, 2011). Egg Mountain was first discovered by a research group from Princeton University in 1979 led by John R. Horner, with subsequent excavation campaigns beginning in 1982 when a quarry extending $\sim 85 \mathrm{~m}^{2}$ was opened on the western slope of the site (Horner, 1984, 1987). The deposits extend for $200 \mathrm{~m}^{2}$ on a small hill and consist of massive calcareous siltstones, associated with discontinuous carbonate layers gently dipping toward the northwest. The succession exposed is characterized by $3 \mathrm{~m}$ of siltstones alternating with a laterally discontinuous and well-indurated calcareous horizon 10-30 cm thick (Fig. 2). Although Lorenz and Gavin (1984) included the site within the lacustrine middle subfacies unit, these deposits have been interpreted as calcitic Inceptisols (Retallack, 1997). Carbonate horizons and the scarcity of root traces argue for a prevalent well-drained soil (Retallack, 1997; Freimuth and Varricchio, 2019). These deposits have yielded a rich fossil collection throughout the succession, consisting of dinosaur

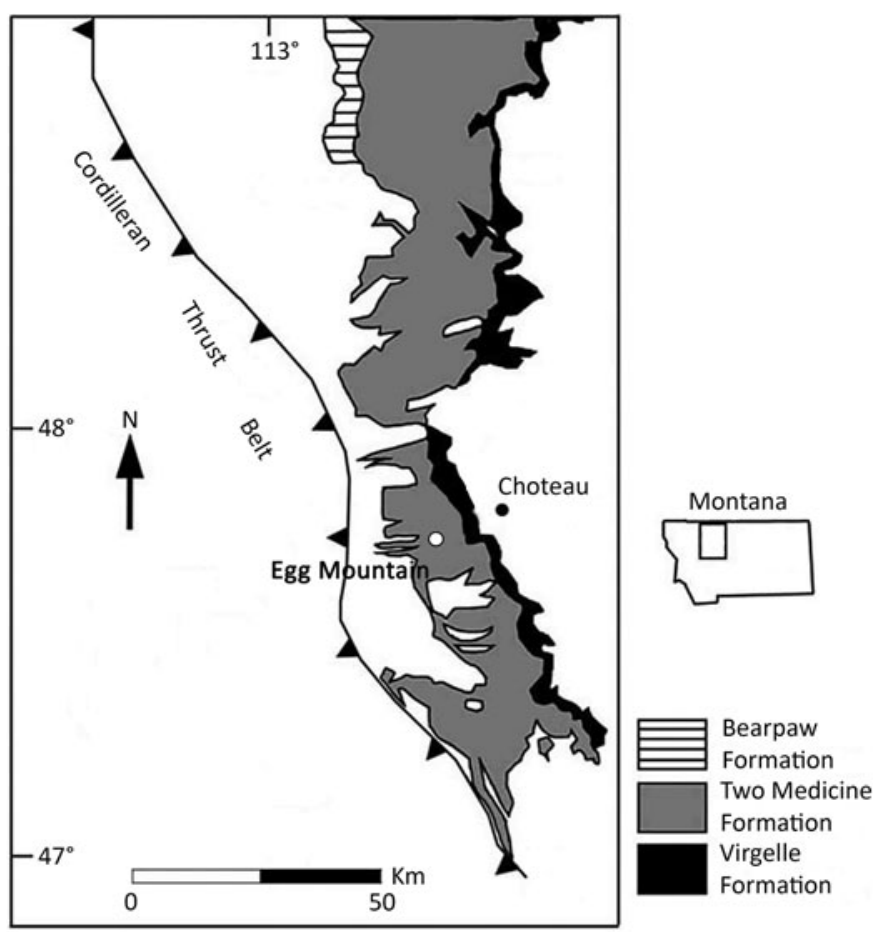

Figure 1. Schematic geological map of northwestern Montana showing the location of Egg Mountain (white dot) (modified from Rogers et al., 2010). remains, eggs, and teeth, lizards, and metatherian and multituberculate mammals, alongside extensive invertebrate bioturbation structures (Montellano, 1988; Horner, 1989; Varricchio et al., 1999; Montellano et al., 2000; Freimuth and Varricchio, 2019). Radiometric analyses place the age of these deposits in the middle Campanian, near 75.5 Ma (Rogers et al., 1993; Varricchio et al., 2010).

\section{Materials and methods}

The material described here comes from the main quarry of Egg Mountain excavated between 2010 and 2016 extending 100 $\mathrm{m}^{2}$, later expanded laterally to the east during the summer of 2015. Excavations exhumed the uppermost $1.5 \mathrm{~m}$ of the succession exposed at the top of Egg Mountain and consisted of first breaking up the indurated lithology with a hand-held 80-pound jack hammer in $\sim 12.5 \mathrm{~cm}$ thick passes. The crew then picked through the generated rubble. The material was also collected in detritus, swept at the edges or floating on the ground surface of the quarry. In total, 95 specimens of the new trace have been collected. Given the absence of discrete strata in the succession, relative abundance of specimens was calculated for each of the 12 jack-hammer passes (JHP) representing artificial timelines across the main quarry. Specimens from the excavations involving the expansion of the main quarry were not included in the abundance analysis because the material could not be related confidently to jack-hammer passes of the main quarry. Only 36 specimens were suitable for measurements. In addition, a few representative specimens were prepared as petrographic thin sections for optical and chemical analyses. A JEOL JSM-6100 scanning electron microscope was used to obtain chemical characterization across the diagnostic area of the samples. Standard thin sections $30 \mu \mathrm{m}$ in thickness were prepared and coated with gold using a sputter coater set with current and time, respectively, at $30 \mathrm{~mA}$ and $30 \mathrm{sec}$. $\mathrm{X}$-ray spectra and relative element total weight percentages were collected using the software Winshell (Ingo H. de Boer,

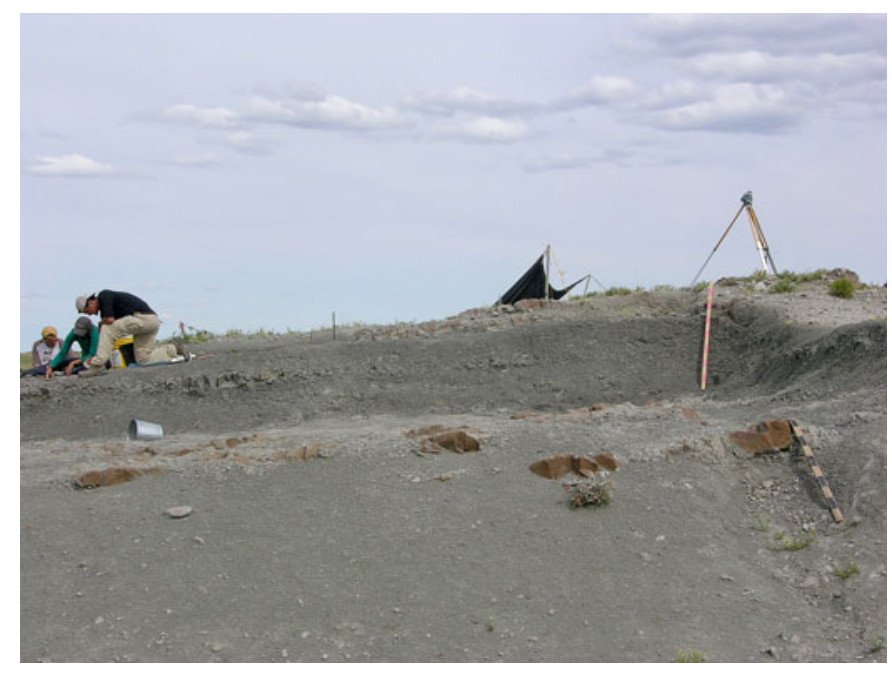

Figure 2. View of the quarry at the Egg Mountain locality showing paleosol deposits characterized by gray calcareous siltstones and prominent laterally discontinuous carbonaceous layers. The beds dip slightly to the north (at left). 
http://www.winshell.org) and visualized using the program WinTools (Godlike Developers, http://www.wintools.net/). The pulse throughput was set at $2.5 \mathrm{Kcps}$ and the amplification at $20 \mathrm{eV}$ per channel to collect from $0-20 \mathrm{kV}$. X-ray spectra were obtained at a death time of $20-30 \%$. The working distance was maintained at $39 \mathrm{~mm}$.

Repository and institutional abbreviation.-Specimens examined in this study are deposited in the Museum of The Rockies (MOR), Bozeman, Montana, USA.

\section{Systematic ichnology}

Ichnofamily Pallichnidae Genise, 2004

Ichnogenus Feoichnus Krause et al., 2008

Type ichnospecies.—Feoichnus challa Krause et al., 2008 by original designation.

Diagnosis.-A hemispherical, concave-up, pan-shaped structure, seldom conical in shape, with an irregular external morphology, and lacking an active filling. The internal surface is smooth and lined, sometimes bearing multiple stained layers. The internal surface can also display irregular ridges or a bumpy appearance. The external surface is irregular and can show a characteristic lateral smooth groove with longitudinal striations that is vertically or subhorizontally oriented (modified after Krause et al., 2008).
Remarks.-The ichnogenus Feoichnus has a global distribution, and a stratigraphic occurrence extending back to the Cretaceous. The fossil record of Feoichnus in North America ranges from the Upper Cretaceous to the Pliocene (Krause et al., 2008). Specimens reported from Two Medicine Formation deposits can be easily distinguished from other co-occurring trace fossils by its unique hemispherical or hemiellipsoidal shape. Other hemispherical ichnogenera potentially comparable to Feoichnus might be Cellicalichnus Genise et al., 2008 and Dagnichnus Genise et al., 2008, but they differ from the first in displaying, respectively, single and multiple radiating, meniscated cells (Genise et al., 2008).

\section{Feoichnus martini new ichnospecies}

Figures 3, 4, 6-8

Type specimens.-Holotype, MOR-IV-3010 B0.16-1, from Two Medicine Formation deposits, Egg Mountain locality (upper Campanian), west of Choteau, Montana, USA. Paratypes (5): MOR-IV-3010 B0.10-1, B0.10-2, B28.12-1, B24.16-2, and B9.13-2; same locality as holotype.

Diagnosis. - Hemispherical to hemiellipsoidal structure with a simple, regular, rounded, lined lower edge, in places composed of a pattern of concentric rings.

Occurrence.-Massive calcareous gray siltstone associated with micritic limestone interpreted as calcitic Inceptisols; Two

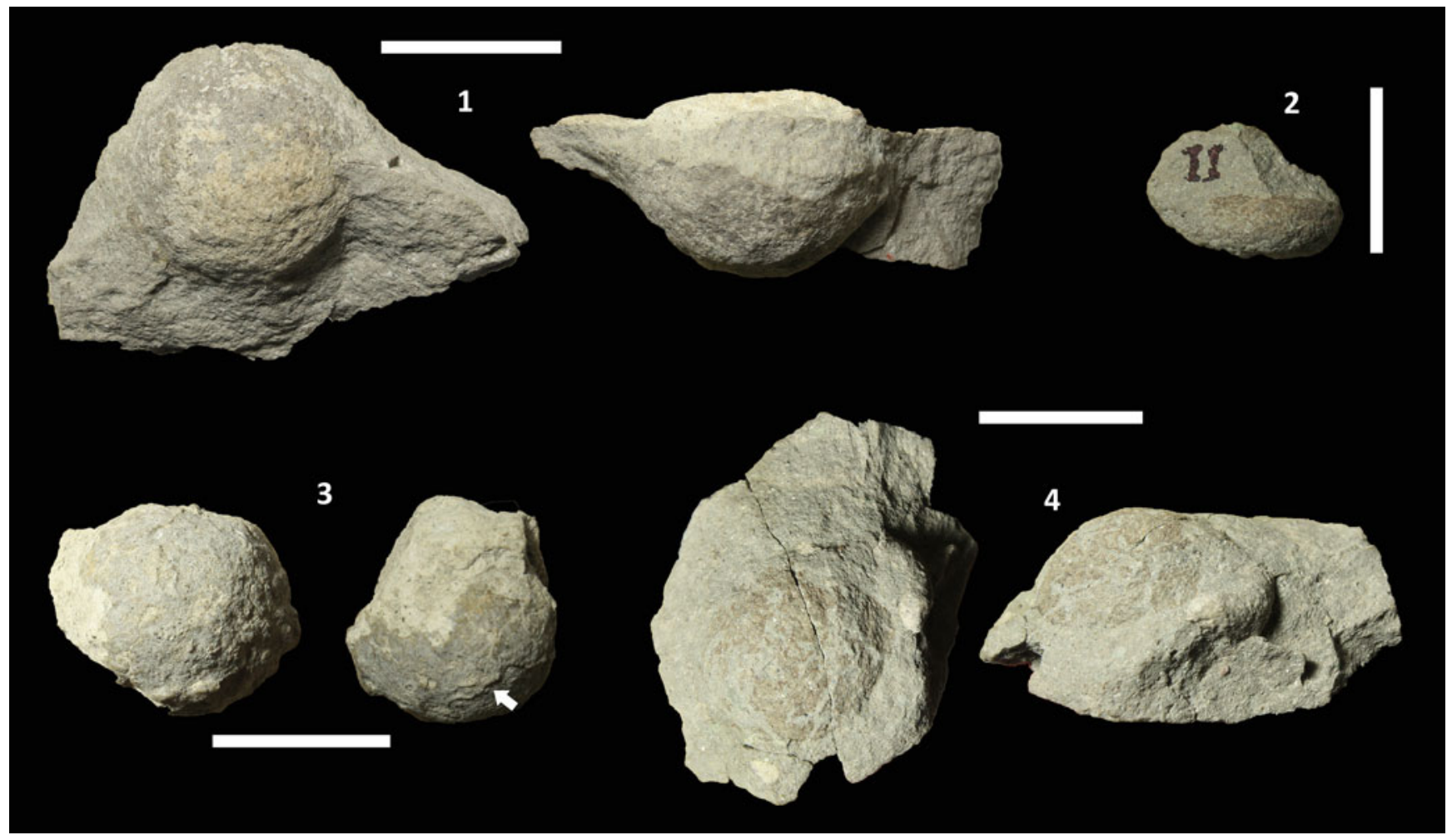

Figure 3. Feoichnus martini n. isp., from Two Medicine Formation deposits at Egg Mountain: (1) holotype MOR-IV-3010 B0.16-1, lower and lateral views; (2) paratype MOR-IV-3010 B0.10-2, lateral view showing distinct brown coloration on its lower half and truncation on the upper edge; (3) paratype MOR-IV-3010 B0.10-1 showing wavy root traces on the lower edge (white arrow); (4) paratype MOR-IV-3010 B24.16-2 partially embedded in host rock. Scale bars $=2 \mathrm{~cm}$. 


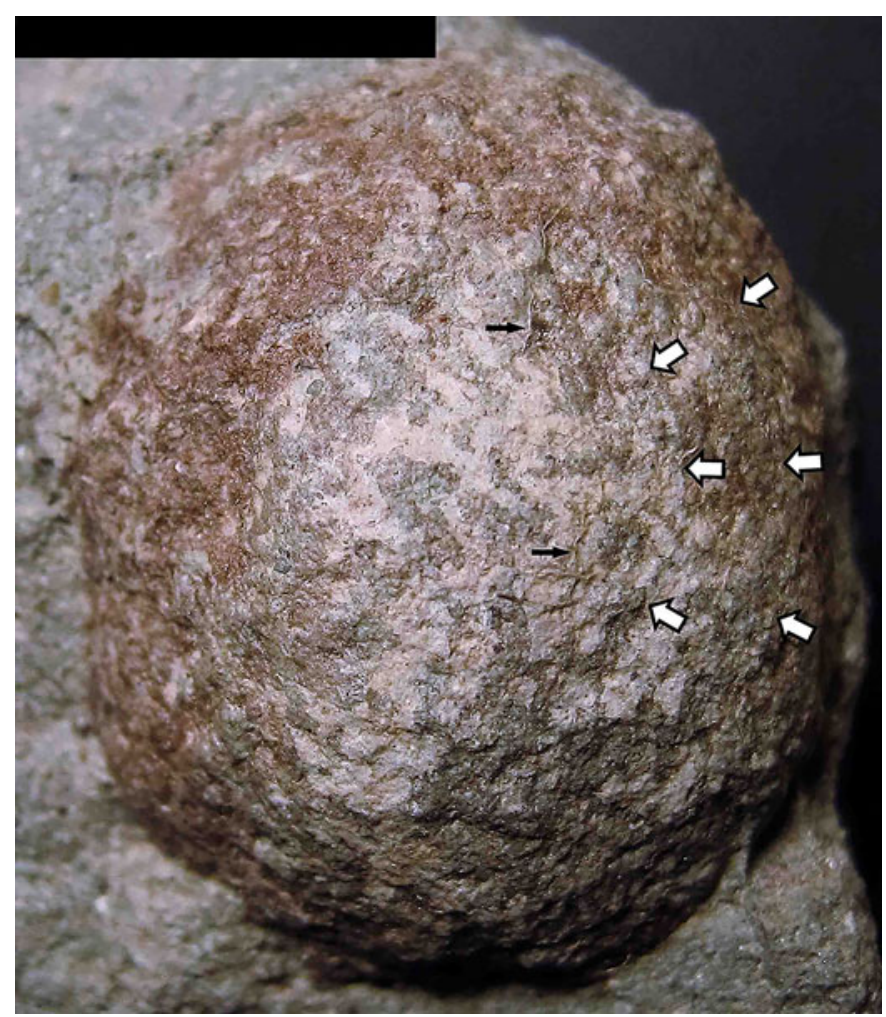

Figure 4. Feoichnus martini n. isp., paratype MOR-IV-3010 B28.12-1, showing thin, branching network of root traces on the surface (black arrows) and pattern of concentric rings on the surface (white arrows). Scale bar $=2 \mathrm{~cm}$.

Medicine Formation at Egg Mountain locality (Upper Campanian), west of Choteau, Montana, USA.

Description.—Specimens ascribed to Feoichnus martini n. isp. are preserved as hemispherical or hemiellipsoidal casts (Fig. 3). In several specimens, the counterpart of the cast is still present and preserved as a regular, rounded, concave mold. The lower border of the cast is rounded, characteristically brown, and can be finely ornamented by wavy, branching lineation, and associated with a pattern of concentric rings (Fig. 4). The brown coloration of the lower surface enhances the visibility of the specimens, making them easily recognizable in the field. In situ specimens are found with the rounded surface directed downward, and the upper edge attached or isolated from the host rock. Thus, the upper edge appears somewhat truncated. Equatorial diameter varies from $4.0-23.9 \mathrm{~mm}$ $(\mathrm{N}=36)$ with most specimens measuring $15-18 \mathrm{~mm}$ (Fig. 5). Height is difficult to estimate unless the structure is completely detached from the host rock, but typically the equatorial diameter exceeds the height.

Etymology.-Feoichnus martini n. isp. is named after paleontologist Anthony J. Martin (Emory University, Atlanta, Georgia, USA) who has greatly contributed to the study and popularization of paleontology and ichnology.

Materials.-In total, 95 specimens with catalog number MOR-IV-3010.

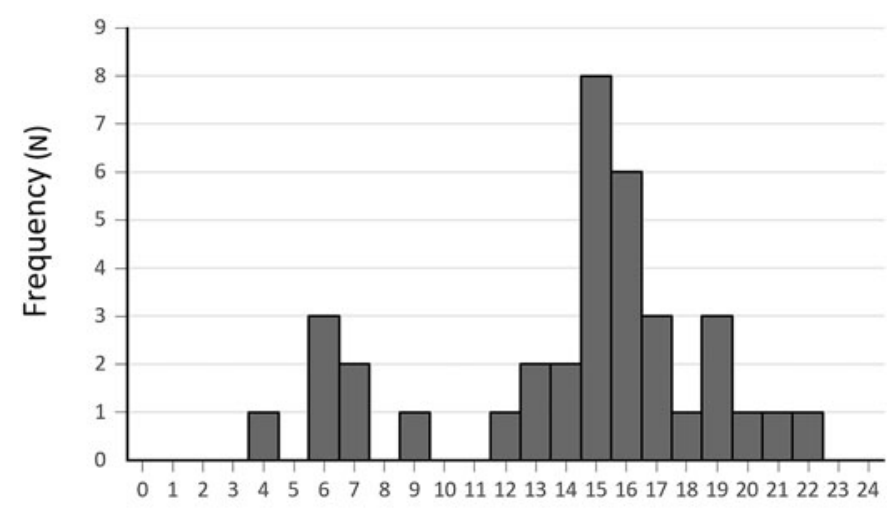

Major axis length $(\mathrm{mm})$

Figure 5. Frequency distribution of Feoichnus martini n. isp. from Egg Mountain, Two Medicine Formation, with respect to major axis length $(\mathrm{N}=36)$.

Remarks.-We establish Feoichnus martini n. isp. on the basis of recurrent shape, size, and composition, and a preservation style that differs from any other trace fossil reported from the Campanian Two Medicine Formation paleosols, as well as on several important features that differentiate it from $F$. challa. Cicada feeding-chamber structures ascribed to $F$. challa are comparable to $F$. martini $n$. isp. in that they display a half-dome shaped form and a lined border. However, the internal structure, orientation, and morphology of $F$. challa indicate the involvement of more complex mechanisms of formation, e.g., readjustment and relative displacement of the chamber (Krause et al., 2008) resulting in a more irregular and variable external trace morphology.

\section{Results}

The filling of the natural casts mainly consists of calcareous siltstone associated with floating angular to subangular clasts of potassium plagioclase, K-felspar, quartz, amphiboles crystals, and lithics. The sediment fill is structureless and

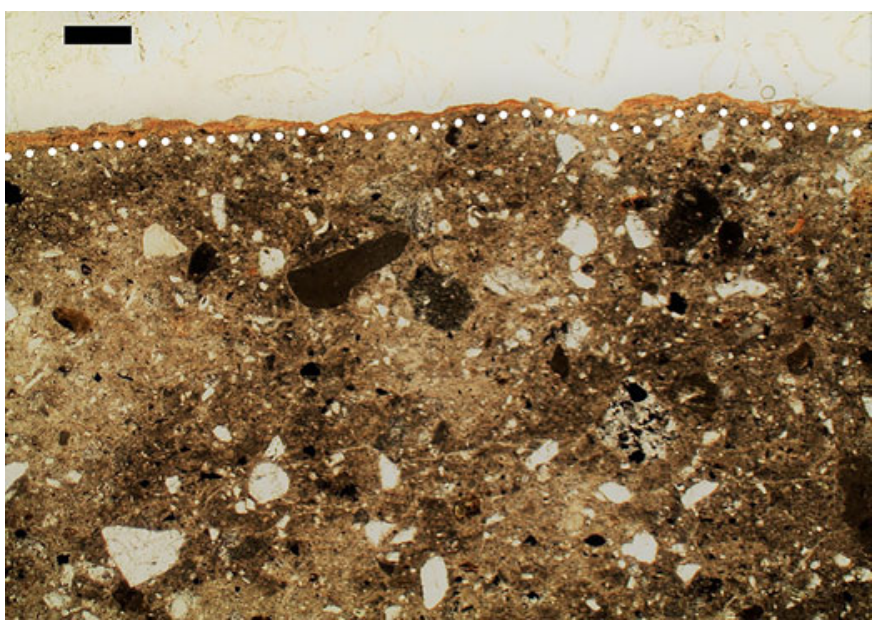

Figure 6. Feoichnus martini n. isp., no catalog number, thin section showing inner filling of a specimen preserved as an isolated cast. White dots emphasize the mineral structure covering the rounded edge of the cast. Scale bar $=0.5 \mathrm{~mm}$. 

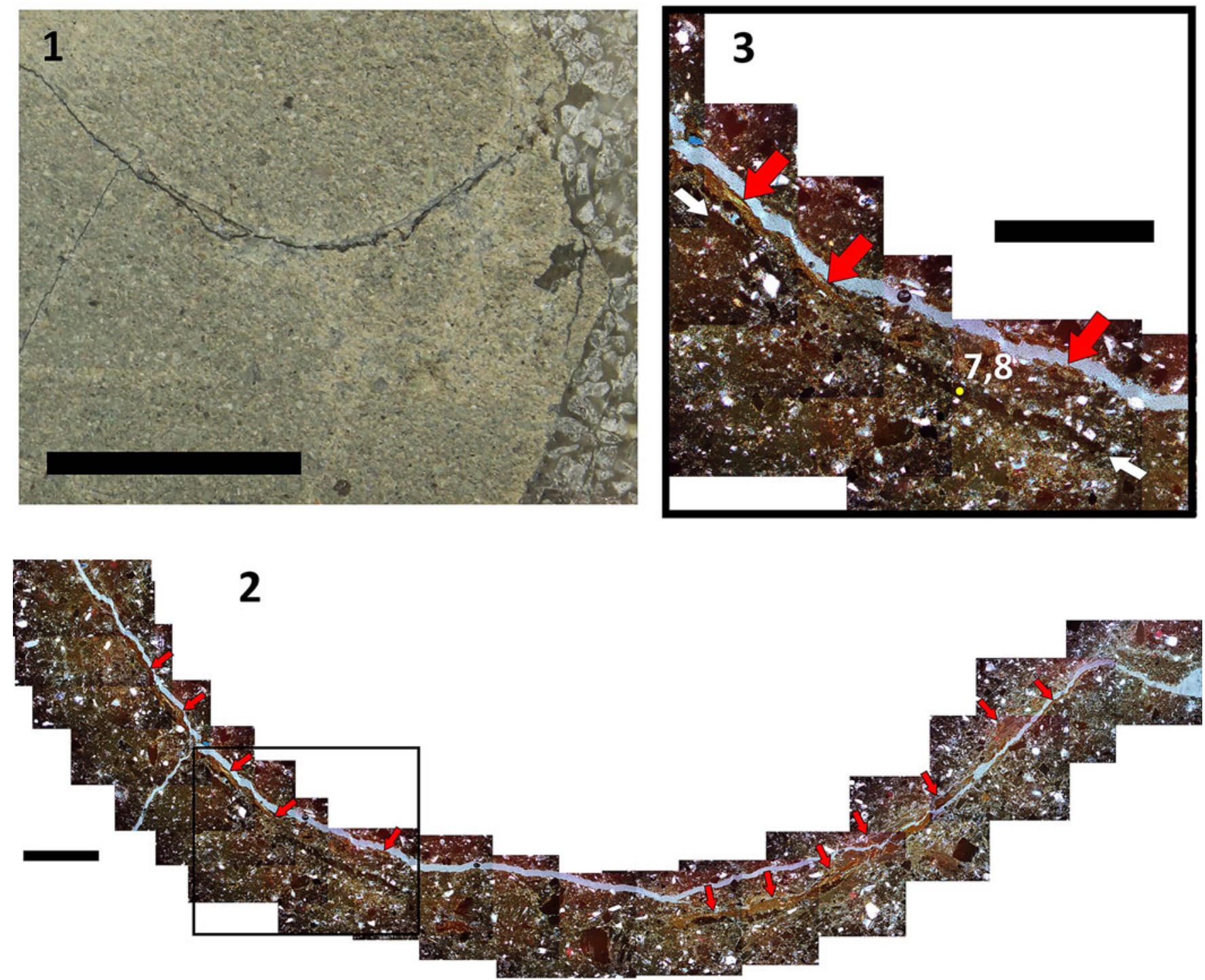

Figure 7. Feoichnus martini $\mathrm{n}$. isp., paratype MOR-IV-3010 B9.13-2, preserved as a cast and its relative impression on the external matrix: (1) polished thin section showing the rounded contact on the lower edge between the inner cast and the outer matrix; (2) composite photomicrographs of the external matrix with details of the mineral structure (red arrows); (3) close-up of the outlined area in (2) showing details of a second, parallel, dark mineral structure (white arrows); yellow dot refers to point 7, 8 where element total weight percentages of the dark mineral structure were measured (Fig. 8). Photomicrographs (2) and (3) in normal polarized light. Scale bars $=2 \mathrm{~cm} \mathrm{(1),} 20 \mathrm{~mm}(\mathbf{2}), 0.5 \mathrm{~mm} \mathrm{(3)}$

compositionally identical to the host rock. The brown coloration observed on the rounded surface appears to be part of a thin discrete mineral structure, which can be traced microscopically along the rounded lower edge. Specimens preserved as isolated casts distinctively display this mineral thin structure on the lower rounded edge, which ranges 50-300 $\mu \mathrm{m}$ in thickness (Fig. 6). In some specimens, the rind has a uniform appearance, but in others, portions are lacking or occupied by a gray, fine-grained, calcareous matrix. This is particularly evident when the specimen is preserved both as a cast and mold (Fig. 7). It is also evident that the mineral structure does not form a complete enclosing border, but rather abruptly terminates within the host rock, defining the detachment line of the half-dome shaped cast. In specimen MOR-IV-3010 B9.13-2, several portions of the rind also adhere to either the cast or the outer matrix. Moreover, a second thin mineral structure has been observed in the outer matrix of this specimen. The structure appears to be separated from the other mineral structure by a thin layer of sediment, is dark in color, always extinct both in normal and crosspolarized lights, and locally incorporates clasts and crystals. Chemical analyses reported total percentages of phosphorus and calcium higher in these two mineral structures with respect to the inner and outer matrix (Fig. 8), therefore defining two phosphorous-rich zones restricted to the lower rounded perimeter.

\section{Discussion}

Consistent size, shape, and orientation argue for a biogenic origin of Feoichnus martini n. isp. The wavy and branching lineations occasionally observed on the lower surface likely represent root traces. These together with the close association of 


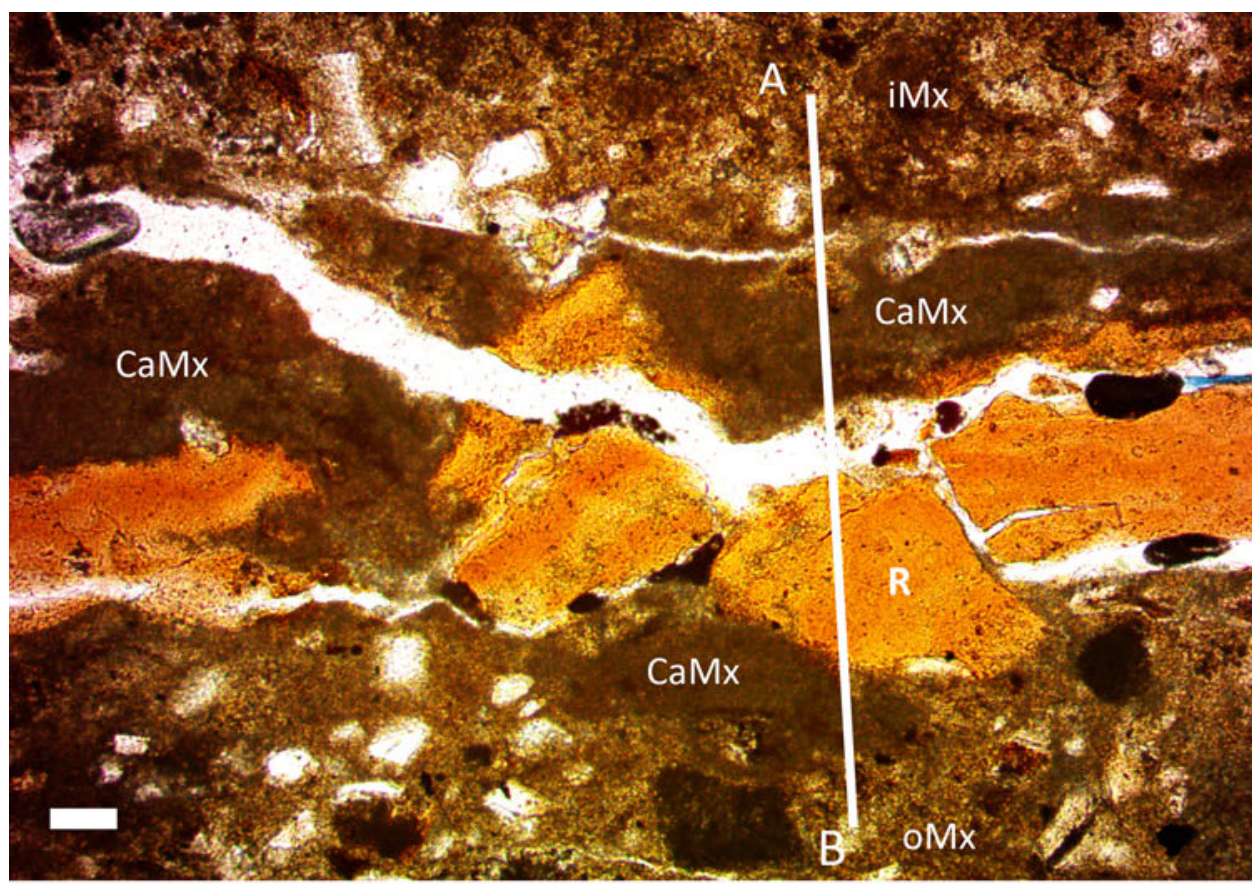

\begin{tabular}{|c|c|c|c|c|c|c|c|c|c|c|c|}
\hline & & $\mathrm{Ca}$ & O & $\mathrm{Fe}$ & Mg & Al & $\mathrm{Si}$ & $\mathbf{P}$ & $\mathrm{Cl}$ & $\mathbf{K}$ & $\mathrm{Na}$ \\
\hline Inner matrix (iMx) & 1 & 9.32 & 52.85 & 2.91 & 1.62 & 6.97 & 23.80 & 3.49 & 0.59 & 2.39 & 1.18 \\
\hline $\begin{array}{l}\text { Fine-grained } \\
\text { calcareous matrix } \\
(\mathrm{CaMx})\end{array}$ & 2 & 16.66 & 43.45 & 1.57 & 1.04 & 4.55 & 13.89 & 6.68 & 0.48 & 0.99 & 0.86 \\
\hline \multirow{2}{*}{$\begin{array}{l}\text { Mineral structure } \\
\text { (R) }\end{array}$} & 3 & 16.49 & 48.27 & 1.64 & 1.07 & 4.48 & 14.00 & 6.40 & 0.44 & 1.00 & 0.92 \\
\hline & 4 & 14.41 & 42.71 & 1.80 & 1.14 & 3.36 & 8.56 & 7.34 & 0.67 & 0.87 & 0.33 \\
\hline \multirow{2}{*}{ Outer matrix (oMx) } & 5 & 8.33 & 49.51 & 2.08 & 1.49 & 4.78 & 14.56 & 4.00 & 0.41 & 1.55 & 0.88 \\
\hline & 6 & 8.28 & 48.78 & 1.97 & 1.38 & 5.64 & 15.74 & 4.28 & 0.35 & 1.68 & 0.67 \\
\hline \multirow{2}{*}{$\begin{array}{c}\text { Dark mineral } \\
\text { structure (see Fig. 7) }\end{array}$} & 7 & 10.87 & 48.85 & 2.48 & 1.76 & 7.59 & 21.39 & 6.84 & 0.31 & 2.58 & 2.01 \\
\hline & 8 & 10.87 & 48.87 & 2.02 & 1.77 & 7.61 & 21.46 & 6.85 & 0.31 & 2.58 & 2.02 \\
\hline
\end{tabular}

1

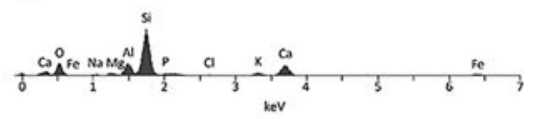

2

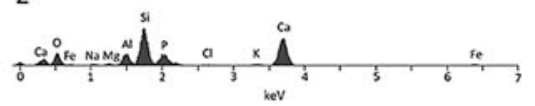

3

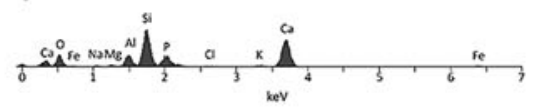

4

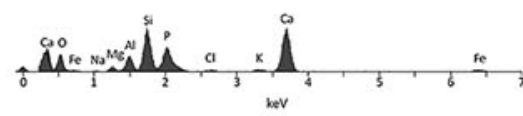

5

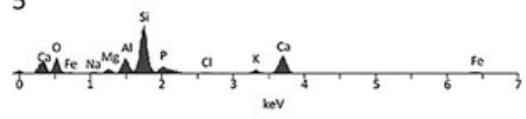

6
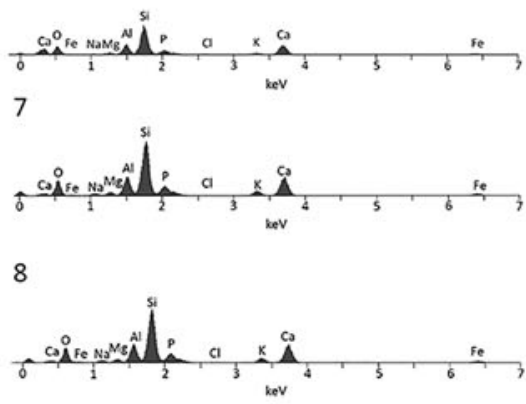

Figure 8. Element total weight percentages and relative X-ray spectra quantified along profile A-B across the cast and the outer matrix of paratype MOR-IV-3010 B9.13-2; photomicrograph in normal polarized light. Data in the table and spectra were attained, respectively, at one point of the cast (iMx), two points in the rind (R), and two points in the outer matrix $(\mathrm{oMx})$. The dark area $(\mathrm{CaMx})$ is composed of a fine-grained calcareous matrix, apparently representing an altered portion of the rind; points 7, 8 are samples of this dark mineral structure (see Fig. 7). Scale bar $=50 \mu \mathrm{m}$. 
Fictovichnus sciuttoi and undetermined burrows indicate that these structures were produced within soil.

As observed in other biogenic structures, the presence of a discrete lower border suggests that Feoichnus martini n. isp. might have been produced by a soil-dwelling organism, and therefore comparison with similar structures produced in soils would help explain its formation and preservation. In F. martini n. isp., at least two thin mineral structures are observed running parallel to the rounded border. These structures are not associated with aligned grains or pellets and tend to incorporate clasts and crystals, suggesting a passive mechanism of formation (i.e., impregnation) rather than mechanical interaction between the trace maker and the substratum (Genise, 2016). Iron has been reported within these structures and oxidation could be responsible for the characteristic rusty color observed on the lower surface. Organic carbon preservation is typically connected with iron oxidation within soils (Kaiser and Guggemberger, 2000; Lalonde et al., 2012). In particular, oxidized horizons and mineral coatings are commonly associated with biogenic structures in which the perimeter is constructed or passively formed by trace makers using organic fluids that compact and stabilize the surrounding sediment (Hallam, 1975; Bromley, 1996; Krause et al., 2008; Genise, 2016). The darker color observed in the most external mineral structure is likely connected to a relatively greater abundance of iron. These mineral structures argue for the presence of organic matter accumulated along the lower rounded border and could be consistent with the presence of multiple stained layers (Genise, 2016). The relatively higher abundance of phosphorous in these mineral structures could also be suggestive of the presence of localized organic matter accumulation. Although calcium carbonate minerals are abundant in Egg Mountain deposits, because they are derived from erosion, transport, and deposition of Paleozoic carbonate sediments (Varricchio et al., 1999), the presence of phosphorus-rich coatings, e.g., collophane minerals, are mainly reported in association with organogenic structures (e.g., dinosaur eggs; Oser, 2014). Thus, although circumstantial, the presence of phosphorus might also be supportive of mineral accumulation derived from an organic source (Retallack, 1984; Karkanas and Goldberg, 2018). The fine-grained calcareous matrix locally observed in close association with these mineral structures is in contrast amorphous, displays irregular contacts, but shows nearly the same phosphorous-rich composition, suggesting that it likely derives from alteration of these mineral structures.

All of the specimens assigned to Feoichnus martini n. isp. are half-dome shaped and lack mineral structure on the upper edge, thus they appear somewhat truncated. With compaction of a complete spherical or prolate morphology, one would still expect these structures to be present, even if deformed. The absence of a discrete upper border was possibly produced by collapse of an unstable sediment. In this scenario, the overall form of $F$. martini n. isp. can be explained if formation of the wall was mainly driven by a passive, gravitational component in which organic discharges concentrated and impregnated the underlying sediment, and hence, consolidated only the lower border (Krause et al., 2008). The absence of oriented grains could support this passive constructional method because the border does not preserve signs of active trace maker-substratum interaction, e.g., oriented grain or fluidized linings. Consequently, this scenario assumes that the structure was initially provided with a roof, but because the discharge of organic fluids selectively consolidated only the bottom of the structure, the roof remained unconsolidated and more prone to collapse. Disruption of the roof eventually caused infilling of the hollow space.

An alternative hypothesis considers the trace maker as more directly the cause of the half-dome shaped structure. For instance, preservation of a half-dome shaped structure could be connected to the emergence of an adult insect from a pupation chamber. However, if this is true, signs of collapse or distortion of the sediment resulting from the emergence should be present, but this does not appear to be the case. Because the main function of an underground chamber is to preserve microclimatic conditions and protection during critical periods, it seems unlikely that construction would not include the presence of a roof (Genise, 2004).

Preservation of Feoichnus martini n. isp. is similar to that reported for $F$. challa. The latter is characterized by a panshaped, passively filled structure with a lined internal surface that can consist of multiple stained layers. Additionally, the external morphology is characteristically irregular and can also present a lateral groove. These complementary features have been interpreted as feeding behavior of the trace maker. Specifically, Krause et al. (2008) reported the presence of the lateral groove in $\sim 40 \%$ of the specimens described, making it a supportive character observed in this trace fossil. Root traces, represented by wavy or mesh-like lineation structures, are common on insect trace fossils from the Two Medicine Formation and are also reported in F. martini n. isp., but none of them are comparable to the lateral groove structure observed in $F$. challa. Furthermore, the overall shape observed in $F$. martini n. isp. is more regular and simpler than that reported in F. challa.

Based on consistent simple shape, size, and orientation, Feoichnus martini n. isp. is here interpreted as a trace constructed in soil. We favor an interpretation in which the mineral structures observed along the lower surface represent the vestigial accumulation of organic fluids released by the trace maker. This process is similar to that observed in soil-dwelling insects, e.g., cicada nymphs, and could be indicative of a lined border composed of multiple stained layers (Krause et al., 2008; Genise, 2016). Traces produced by soil-dwelling organisms, e.g., burrows and chambers used for feeding, nesting, hibernation, or aestivation purposes, typically display a discrete border (Retallack, 1984; Edwards et al., 1998; Downing, 2004; Betadou et al., 2008; Alonso-Zarza et al., 2014; Genise and Harrison, 2018). Pupation and nesting structures, i.e., Pupichnia and Calichnia, resulting from insect activity are one of the most common structures encountered in paleosols, but their walls are generally too complex to be attributed to $F$. martini n. isp. The pattern of concentric rings sometimes observed on the lower edge of $F$. martini $n$. isp. might indicate that the trace maker excavated the structure within soil. Alternatively, the rings could have resulted from lithostatic compaction of a more truly spherical structure. Regardless, the characteristic regular, rounded external morphology suggests that the trace maker remained in a more or less static position. Moreover, because F. martini n. isp. does not display a lateral groove, possible 
assignment to a cicada feeding chamber remains tenuous to problematic. Ultimately, F. martini $\mathrm{n}$. isp. could represent a structure produced by a soil-dwelling insect, but, given its simple morphology, no definitive identification can be confirmed about its function or specific trace maker.

Egg Mountain deposits are notable for the peculiar impoverished Celliforma ichnofacies, characterized for the most part by Fictovichnus sciuttoi, an ichnotaxon interpreted as produced by fossorial wasps, which suggests both well-drained soil conditions for the majority of the year and a workable substratum ideal for soil-dwelling organisms (Genise et al., 2010; Genise, 2016; Freimuth and Varricchio, 2019). Feoichnus martini $\mathrm{n}$. isp. is relatively more abundant in the uppermost $25 \mathrm{~cm}$ of the deposit where the greatest ichnodiversity has been reported (Table 1). Jack-hammer passes have yield three morphotypes ascribed to Fictovichnus sciuttoi, possible Fictovichnus isp., unidentified invertebrate burrows (Freimuth and Varricchio, 2019), and a clutch-associated dinosaur nest (Varricchio et al., 1999). Co-occurrence of dinosaur egg clutches, and vertebrate and invertebrate trace fossils suggests a complex trophic web in which organisms could have exploited a broad variety of potential food resources (Horner, 1982, 1984, 1989; Chin and Gill, 1996; Varricchio et al., 1997, 1999; DeMar et al., 2017).

Krause et al. (2008) interpreted the wall of Feoichnus challa as a passively lined wall consisting of an inner lining and the portion of the soil surrounding the excavated chamber that was originally impregnated with organic fluids, a definition that is also applied here to Feoichnus martini $\mathrm{n}$. isp. They further suggested that thinning of the wall observed in Feoichnus specimens from different stratigraphic horizons of the Sarmiento Formation could be in response to increasingly drier climates. The lined wall of $F$. martini $i$. isp. is markedly thin compared to the overall dimensions of the structure and could be consistent with the well-drained condition of the soil informed by the ichnoassemblage reported at Egg Mountain (Freimuth and Varricchio, 2019).

So far, this report is the only occurrence of Feoichnus martini n. isp. from the Two Medicine Formation. The limited distribution could be connected to local ecological parameters, e.g., temperature and soil moisture, particularly suitable for the trace maker (Brockmann, 1979; Lorenz and Gavin, 1984;

Table 1. Relative abundance of Fictovichnus isp. and Feoichnus martini n. isp. across jack-hammer passes (JHP) of the main quarry (modified after Freimuth and Varricchio, 2019).

\begin{tabular}{|c|c|c|c|c|c|}
\hline & \multicolumn{4}{|c|}{ Fictovichnus isp. } & \multirow[b]{2}{*}{ Feoichnus martini $\mathrm{n}$. isp } \\
\hline & Small & Medium & Large & Wide & \\
\hline JHP 1 & 43 & 16 & 17 & 3 & 8 \\
\hline JHP 2 & 35 & 66 & 58 & 18 & 28 \\
\hline JHP 3 & 85 & 191 & 44 & 0 & 1 \\
\hline JHP 4 & 29 & 43 & 28 & 7 & 6 \\
\hline JHP 5 & 42 & 22 & 6 & 19 & 1 \\
\hline JHP 6 & 148 & 166 & 52 & 54 & 5 \\
\hline JHP 7 & 160 & 234 & 13 & 1 & 7 \\
\hline JHP 8 & 89 & 321 & 13 & 0 & 9 \\
\hline JHP 9 & 158 & 467 & 3 & 0 & 0 \\
\hline JHP 10 & 118 & 131 & 4 & 0 & 0 \\
\hline JHP 11 & 103 & 152 & 22 & 0 & 0 \\
\hline JHP 12 & 203 & 220 & 42 & 15 & 5 \\
\hline TOTAL & 1213 & 2029 & 302 & 117 & 70 \\
\hline
\end{tabular}

O’Neill, 2001, p. 283; Genise et al., 2000; Martin and Varricchio, 2011), or it could reflect the extensive and focused collecting techniques applied at the site in search of small vertebrates (DeMar et al., 2017). Paleosols stratigraphically equivalent to the Egg Mountain deposits are abundant in the Willow Creek Anticline area, but only a few have been studied in detail (Martin and Varricchio, 2011; Freimuth and Varricchio, 2019). Further field discoveries from new localities will be helpful to better understand the nature of this enigmatic trace fossil.

\section{Conclusions}

Feoichnus martini $\mathrm{n}$. isp. consists of a hemispherical or hemiellipsoidal structure characterized by a regular, rounded lower border and a lined wall. The structure is recurrent throughout the Egg Mountain succession and is closely associated with extensive invertebrate bioturbation. The wall of $F$. martini n. isp. was likely produced by the release of organic fluids by the trace maker, resulting in multiple stained layers. Feoichnus martini $\mathrm{n}$. isp. is here interpreted as a structure likely constructed by a soil-dwelling invertebrate, although its function and specific trace maker are still disputable. This trace fossil represents an important addition to the ichnoassemblages mainly composed of Pupichnia and extends the record of the ichnogenus Feoichnus to the Campanian deposits of Montana.

\section{Acknowledgments}

The authors would like to thank J.F. Genise and K. Chin whose advice and discussions were inspirational and stimulating for this study; W.J. Freimuth who reviewed and helped improve the manuscript, as well as A. Atwater and A. Moore-Nall. The authors are also grateful to the staff of the Imaging and Chemical Analysis Laboratory of Montana State University who provided the instruments for imaging and chemical analyses. A special mention is due to A.J. Martin, the enigmatic ichnologist who inspired the name of the enigmatic Feoichnus martini n. isp., and last but not least, all of the the field crews of Egg Mountain 2010-2016 (AKA the Egg Mountaineers and Rubble Pickers). We also thank Associate Editor G. Mángano and four anonymous reviewers who helped to improve the manuscript. In addition, the first author offers grateful acknowledgment to U. Nicosia for his support and for reviewing the first draft of the manuscript.

\section{References}

Alonso-Zarza, A.M., Genise, J.F., and Verde, M., 2014, Paleoenvironments and ichnotaxonomy of insect trace fossils in continental mudflat deposits of the Miocene Calatayud-Daroca Basin, Zaragoza, Spain: Palaeogeography, Palaeoclimatology, Palaeoecology, v. 414, p. 342-351, doi:10.1016/ j.palaeo.2014.09.012.

Bedatou, E., Melchor, R.N., Bellosi, E., and Genise, J.F., 2008, Crayfish burrows from Late Jurassic-Late Cretaceous continental deposits of Patagonia: Argentina: Their palaeoecological, palaeoclimatic and palaeobiogeographical significance: Palaeogeography, Palaeoclimatology, Palaeoecology, v. 257, p. 169-184, doi:10.1016/j.palaeo.2007.09.020.

Brockmann, H., 1979, Nest-site selection in the great golden digger wasp, Sphex ichneumoneus L. (Sphecidae): Ecological Entomology, v. 4, no. 3, p. 211224.

Bromley, R.G., 1996, Trace Fossils: Biology, Taxonomy and Applications: New York, Routledge, 378 p. 
Buatois, L.A., and Mángano, M.G., 2011, Ichnology: Organism-substrate Interactions in Space and Time: New York, Cambridge University Press, 12 p.

Chin, K., and Gill, B.D., 1996, Dinosaurs, dung beetles, and conifers: Participants in a Cretaceous food web: Palaios, v. 11, p. 280-285.

DeMar, D.G., Jr., Conrad, J.L., Head, J.J., Varricchio, D.J., and Wilson, G.P., 2017, A new Late Cretaceous iguanomorph from North America and the origin of New World Pleurodonta (Squamata, Iguania): Proceedings of the Royal Society, B: Biological Sciences, v. 284, no. 1847, p. 20161902, doi:10.1098/rspb.2016.1902.

Downing, H., 2004, Construction behavior of insects, in Capinera, J.L., ed., Encyclopedia of Entomology: Heidelberg, Springer Netherlands, p. 605-613.

Edwards, N., Jarzembowski, E.A., Pain, T., and Daley, B., 1998, Cocoon-like trace fossils from the lacustrine-palustrine Bembridge Limestone Formation (late Eocene), southern England: Proceedings of the Geologists' Association, v. 109 , no. 1 , p. $25-32$.

Falcon-Lang, H.J., 2003, Growth interruptions in silicified conifer woods from the Upper Cretaceous Two Medicine Formation, Montana, USA: Implications for palaeoclimate and dinosaur palaeoecology: Palaeogeography, Palaeoclimatology, Palaeoecology, v. 199, p. 299-314, doi:10.1016/ S0031-0182(03)00539-X.

Freimuth, J.W., and Varricchio, J.D., 2019, Insect trace fossils elucidate depositional environments and sedimentation at a dinosaur nesting site from the Cretaceous (Campanian) Two Medicine Formation of Montana: Palaeogeography, Palaeoclimatology, Palaeoecology, v. 534, p. 109262, doi:10.1016/j.palaeo.2019.109262.

Genise, J.F., 2004, Ichnotaxonomy and ichnostratigraphy of chambered trace fossils in palaeosols attributed to coleopterans, ants and termites: Geological Society, London, Special Publications, v. 228, no. 1, p. 419-453, doi:10.1144/GSL.SP.2004.228.01.19.

Genise, J.F., 2016, Ichnoentomology: Insect Traces in Soils and Paleosols: New York, Springer, $565 \mathrm{p}$.

Genise, J.F. and Harrison, T., 2018, Walking on ashes: Insect trace fossils from Laetoli indicate poor grass cover associated with early hominin environments: Palaeontology, v. 61 , no. 4, p. 1-28, doi:10.1111/pala.12357.

Genise, J.F., Mángano, M.G., Buatois, L.A., Laza, J.H., and Verde, M., 2000, Insect trace fossil associations in paleosols: The Coprinisphaera ichnofacies: Palaios, v. 15, p. 49-64, doi:10.1669/0883-1351(2000)015<0049: ITFAIP $>2.0 . \mathrm{CO} ; 2$.

Genise, J.F., Melchor, R.N., Bellosi, E.S., González, M.G., and Krause, M., 2007, New insect pupation chambers (Pupichnia) from the Upper Cretaceous of Patagonia, Argentina: Cretaceous Research, v. 28, p. 545-559, doi:10.1016/j.cretres.2006.08.007.

Genise, J.F., Bedatou, E., and Melchor, R.N., 2008, Terrestrial crustacean breeding trace fossils from the Cretaceous of Patagonia (Argentina) Palaeobiological and evolutionary significance: Palaeogeography, Palaeoclimatology, Palaeoecology, v. 264, p. 128-139, doi:10.1016/ j.palaeo.2008.04.004.

Genise, J.F., Melchor, R.N., Bellosi, E.S., and Verde, M., 2010, Invertebrate and vertebrate trace fossils from continental carbonates: Developments in Sedimentology, v. 61, p. 319-369, doi:10.1016/S0070-4571(09)06107-X.

Genise, J.F., Bedatou, E., Bellosi, E.S., Sarzetti, L.C., Sánchez, M.V., and Krause, J.M., 2016, The Phanerozoic four revolutions and evolution of paleosol ichnofacies, in Mángano, M., and Buatois, L., eds., The Trace Fossil Record of Major Evolutionary Events: Dordrecht, Springer, p. 301-370.

Hallam, A., 1975, Preservation of trace fossils, in Frey, R.W., ed., The Study of Trace Fossils: New York, Springer-Verlag, p. 55-63.

Horner, J.R., 1982, Evidence of colonial nesting and site fidelity among ornithischian dinosaurs: Nature, v. 297, p. 675.

Horner, J.R., 1984, The nesting behavior of dinosaurs: Scientific American, v. 250 , no. 4 , p. $130-137$.

Horner, J.R., 1987, Ecologic and behavioral implications derived from a dinosaur nesting site, in Czerkas, S.J., ed., Dinosaurs Past and Present, Volume 2: Seattle, University of Washington Press, p. 50-63.

Horner, J.R., 1989, The Mesozoic terrestrial ecosystems of Montana, in French, D.E., and Grabb, R.F., eds., Montana Geological Society Field Conference Guidebook: Montana Centennial Edition, Geologic Resources of Montana: [Billings], Montana Geological Society, p. 153-162.
Karkanas, P., and Goldberg, P., 2018, Phosphatic features, in Stoops, G., Marcelino, V., and Mees, F., eds., Interpretation of Micromorphological Features of Soils and Regoliths (second edition): Cambridge, Elsevier, p. 323-346.

Kaiser, K., and Guggenberger, G., 2000, The role of DOM sorption to mineral surfaces in the preservation of organic matter in soils: Organic Geochemistry, v. 31, p. 711-725, doi:10.1016/S0146-6380(00)00046-2.

Krause, J., Bown, T.M., Bellosi, E.S., and Genise, J.F., 2008, Trace fossils of cicadas in the Cenozoic of central Patagonia, Argentina: Palaeontology, v. 51, p. 405-418, doi:10.1111/j.1475-4983.2008.00753.x.

Lalonde, K., Mucci, A., Ouellet, A., and Gélinas, Y., 2012, Preservation of organic matter in sediments promoted by iron: Nature, v. 483 , no. 7388 , p. 198-200, doi:10.1038/nature 10855 .

Lorenz, J.C., and Gavin W., 1984, Geology of the Two Medicine Formation and the sedimentology of a dinosaur nesting ground, in McBane, J.D., and Garrison, P.B., eds., Montana Geological Society 1984 Field Conference Guidebook: Helena, Montana Geological Society, p. 175-186.

Martin, A.J., and Varricchio, D.J., 2011, Paleoecological utility of insect trace fossils in dinosaur nesting sites of the Two Medicine Formation (Campanian), Choteau, Montana: Historical Biology, v. 23, p. 15-25, doi: $10.1080 / 08912963.2010 .505285$.

Montellano, M., 1988, Alphadon halleyi (Didelphidae, Marsupialia) from the Two Medicine Formation (Late Cretaceous, Judithian) of Montana: Journal of Vertebrate Paleontology, v. 8, no. 4, p. 378-382.

Montellano, M., Weil, A., and Clemens, W.A., 2000, An exceptional specimen of Cimexomys judithae (Mammalia: Multituberculata) from the Campanian Two Medicine Formation of Montana, and the phylogenetic status of Cimexomys: Journal of Vertebrate Paleontology, v. 20, no. 2, p. 333-340, doi:10.1671/0272-4634(2000)020[0333:AESOCJ]2.0.CO;2.

O'Neill, K.M., 2001, Solitary Wasps: Behavior and Natural History: Ithaca, Cornell University Press, 283 p.

Oser, S.E., 2014, Fossil eggs and perinatal remains from the Upper Cretaceous Two Medicine Formation of Montana: Description and implications [Ph.D. dissertation]: Bozeman, Montana State University, $135 \mathrm{p}$.

Retallack, G.J., 1984, Trace fossils of burrowing beetles and bees in an Oligocene paleosol, Badlands National Park, South Dakota: Journal of Paleontology, v. 58, p. 571-592.

Retallack, G.J., 1997, Dinosaurs and dirt, in Wolberg, D.L., Stump, E., and Rosenberg, G.D., eds., DinoFest International: Proceedings of a Symposium Sponsored by Arizona State University: Philadelphia, Academy of Natural Sciences, p. 345-359.

Rogers, R.R., 1990, Taphonomy of three dinosaur bone beds in the Upper Cretaceous Two Medicine Formation of northwestern Montana: Evidence for drought-related mortality: Palaios, v. 5, p. 394-413.

Rogers, R.R., Swisher, C.C., and Horner, J.R., 1993, ${ }^{40} \mathrm{Ar}^{39}{ }^{9} \mathrm{Ar}$ age and correlation of the nonmarine Two Medicine Formation (Upper Cretaceous), northwestern Montana, U.S.A.: Canadian Journal of Earth Science, v. 30, p. 1066-1075.

Rogers, R.R., Fricke, H.C., Addona, V., Canavan, R.R., Dwyer, C.N., Harwood, C.L., Koenig, A.E., Murray, R., Thole, J.T., and Williams, J., 2010, Using laser ablation-inductively coupled plasma-mass spectrometry (LA-ICP-MS) to explore geochemical taphonomy of vertebrate fossils in the Upper Cretaceous Two Medicine and Judith River formations of Montana: Palaios, v. 25 , no. 3, 183-195, doi:10.2110/palo.2009.p09-084r.

Savrda, C.E., 2007, Taphonomy of trace fossils, in Miller, W., III, ed., Trace Fossils: Oxford, Elsevier, p. 92-109.

Varricchio, D.J., Jackson, F., Borkowski, J.J., and Horner, J.R., 1997, Nest and egg clutches of the dinosaur Troodon formosus and the evolution of avian reproductive traits: Nature, v. 385 , no. 6613, p. 247-250.

Varricchio, D.J., Jackson, F., and Trueman, C.N., 1999, A nesting trace with eggs for the Cretaceous theropod dinosaur Troodon formosus: Journal of Vertebrate Paleontology, v. 19, no. 1, p. 91-100.

Varricchio, D.J., Koeberl, C., Raven, R.F., Wolbach, W.S., Elsik, W.C., and Miggins, D.P., 2010, Tracing the Manson impact event across the Western Interior Cretaceous Seaway: Geological Society of America Special Papers, v. 465 , p. $269-299$, doi:10.1130/2010.2465(17).

Accepted: 8 April 2020 